\title{
MELKERSSON ROSENTHAL SYNDROME-MIMICKER OF ANGIOEDEMA
}

\author{
MD ROBED AMIN ${ }^{1}$, SABBIHA NADIA MAJUMDER ${ }^{2}$
}

Received: 08 December 2016

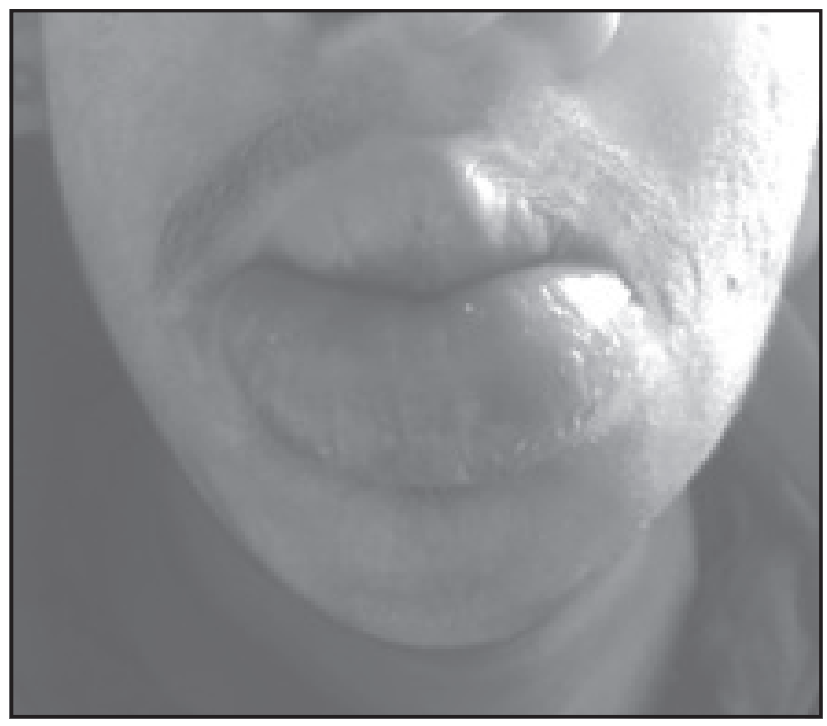

16-year old Bangladeshi boy, who was admitted to the Dhaka Medical College Hospital with the complaint of persistent swelling of his lips especially lower one for two years. The swelling was not associated with tenderness, itching, any trauma or injection of any foreign material to the area. There was also no associated hives or swelling of any other areas. On physical examination, the lower lips were predominantly red, swollen, painless and thickens. On opening of mouth the tongue was found to have a longitudinal fissure extending from middle to epiglottis. The oral cavity, gum and posterior wall of pharynges were congested and inflamed. The narrowing was observed at posterior end. Investigations were done to exclude Crohn's disease, sarcoid, tuberculosis and foreign body reactions ${ }^{1}$.CT chest were unremarkable. A video bronchoscopy was attempted, however unsuccessful due to the scope not being able to be negotiated through the oedematous epiglottitis and laryngeal wall. Tissue from the upper lip was reported as showing infiltrate
Accepted: 28 May 2017

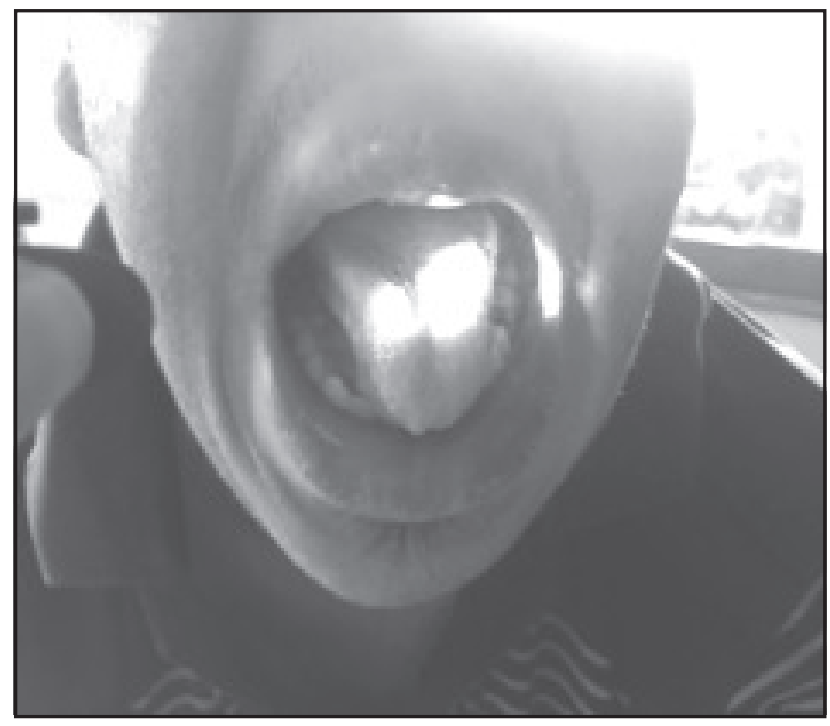

from chronic inflammatory cells including non caseating granuloma and consistent with granulomatous cheilitis ${ }^{2}$. He was diagnosed as a case of Melkersson Rosenthal Syndrome (variant of orofacial granulomatosis or granulomatous cheilitis). Although facial nerve palsy was not present during presentation, It should be stressed that it is rare for all components of the Melkersson-Rosenthal syndrome to occur at the same time and many a time ${ }^{3}$ , this facial sign can only be found after several years of follow-up.

\section{References:}

1. Leao, J. C., Hodgson, T., Scully, C., \& Porter, S. (2004). Review article: orofacial granulomatosis. Alimentary Pharmacology \& Therapeutics, 20(10), 10191027. doi: $10.1111 / \mathrm{j} .1365-2036.2004 .02205 . x$

2. Melkersson E. Ett fall av recidiverande facialispares i samband med angioneurotiskt ödem. Hygiea (Stockh)1928;90: 737-741.

3. Greene RM, Rogers RS, 3rd. Melkersson-Rosenthal syndrome: a review of 36 patients. J Am Acad Dermatol 1989; 21:1263-1270.

1. Associate Prof of Medicine, Dept of Medicine, Dhaka Medical College

2. Medical Officer, Dept of Medicine, Dhaka Medical College

Address of Correspondence: Dr. Md Robed Amin, Associate Prof of Medicine, Dept of Medicine, Dhaka Medical College 